\title{
Oral coinfection can stress peripheral lymphocyte to inflammatory activity in leprosy
}

\author{
Ana Carolina Fragoso Motta ${ }^{[1]}$, João Carlos Lopes Simão ${ }^{[1]}$, Renata Bazan Furini ${ }^{[1]}$, \\ Maria Aparecida Nunes Ferreira ${ }^{[1]}$, Patrícia Vianna Bonini Palma ${ }^{[2]}$, \\ Marilena Chinali Komesu ${ }^{[3]}$ and Norma Tiraboschi Foss ${ }^{[1]}$
}

[1]. Divisão de Dermatologia, Faculdade de Medicina de Ribeirão Preto, Universidade de São Paulo, Ribeirão Preto, SP. [2]. Hemocentro, Faculdade de Medicina de Ribeirão Preto, Universidade de São Paulo, Ribeirão Preto, SP. [3]. Departamento de Morfologia, Estomatologia e Fisiologia, Faculdade de Odontologia de Ribeirão Preto, Universidade de São Paulo, Ribeirão Preto, SP.

\begin{abstract}
Introduction: This study evaluated the intracellular profile of interleukin-2 (IL-2), interleukin-4 (IL-4), interleukin-10 (IL-10) and interferon- $\gamma(\mathrm{IFN}-\gamma)$ in peripheral blood mononuclear cells (PBMCs) from leprosy patients based on oral infections presence to determine whether these coinfections could be associated with pro-inflammatory activity in leprosy. Methods: Leprosy patients regardless of clinical form and specific leprosy treatment $(\mathrm{n}=38)$ were divided into two groups: Group I - leprosy patients with oral infections ( $\mathrm{n}=19)$, and Group II - leprosy patients without oral infections $(\mathrm{n}=19)$. Non-leprosy patients presenting oral infections were assigned to the control Group ( $\mathrm{n}=10)$. Intracellular IL-2, IL-4, IL-10 and IFN- $\gamma$ production was evaluated by flow cytometry (FACS) before and 7 days after controlling the oral infection in the Group I, before and 7 days after dental prophylaxis in the Group II, and during oral infection process in control Group. Results: Low percentages of CD3+ lymphocytes bearing IL-2, IL-10 and IFN- $\gamma$ were observed in the Group I and Group II at baseline and 7 days after therapy or prophylaxis compared to controls. Group I showed reduced percentages of IL-4 at baseline and 7 days after therapy compared to controls, or at baseline of Group II, and the Group II showed reduced percentages of $\mathrm{CD}^{+}$cells bearing IL-4 compared to control. An increase of the percentages of $\mathrm{CD}^{+}$cells bearing IL-4 was observed in the Group I after the oral infections treatment. Conclusions: The occurrence of oral infections favors the intracellular cytokines expression and, probably, the inflammatory reaction operating as a stimulatory signal triggering the leprosy reactions.
\end{abstract}

Keywords: Leprosy reaction. Mycobacterium leprae. Oral infection. Coinfection. Cytokines. Intracellular staining.

\section{INTRODUCTION}

Leprosy reactional episodes consist of acute inflammatory episodes and are complex situations of the course of the disease. The understanding of the physiopathology of these episodes is fundamental to facilitate the treatment and control of leprosy, since these reactions can be responsible for much of the permanent nerve damage leading to disability and deformities ${ }^{1-3}$.

Cytokine measurement during the reactional episodes has been reported in many studies, especially $\mathrm{T}$ cell biomarkers analyzed in plasma, serum, skin lesions and saliva ${ }^{3-10}$, demonstrating their potential to play a significant role in the classification, prognosis and evolution of leprosy. We have been studying the relationship between these episodes and infectious processes such as chronic oral infections ${ }^{11}$. Since oral infections can induce over-stimulation of the host immune

\footnotetext{
Address to: $\mathrm{Dr}^{\mathrm{a}}$ Ana Carolina Fragoso Motta. Depto Clínica Médica/FMRP/USP. Av. Bandeirantes 3900, 14049-900 Ribeirão Preto, SP, Brasil.

Phone/Fax: 5516 3633-0236

e-mail: anacfm@usp.br

Received in 06/08/2012

Accepted in 15/01/2013
}

system through the release of inflammatory peptides ${ }^{12,13}$, it is reasonable to consider the possibility that these infectious processes act as an inducing and exacerbating or maintaining factor of leprosy reactions. Therefore, it seems important to determine the immune-cellular behavior in leprosy patients with oral infections to investigate whether this coinfection could influence the course of leprosy disease.

In a previous study evaluating the expression of proinflammatory serum biomarkers we observed that leprosy patients with oral infections presented more leprosy reactions associated with higher C-reactive protein (CRP), chemokine IP-10, interleukin-1 (IL-1) and interleukin-6 (IL-6) levels than leprosy patients without oral infections, suggesting that oral infections can act as a maintenance factor of the proinflammatory state ${ }^{14,15}$. However, these results do not show the real participation of peripheral blood cells and the amount of cytokines produced by each cell population, compromising the understanding of the inflammatory response. Thus, the aim of this study was to determine the intracellular profile of proinflammatory cytokines [interleukin-2 (IL-2) and interferon- $\gamma$ (IFN- $\gamma$ )] and anti-inflammatory cytokines (IL-4 and IL-10), in peripheral blood mononuclear cells (PBMCs) from leprosy patients stratified according to the presence of chronic oral infections to determine whether these coinfections could be associated with pro-inflammatory activity in leprosy. 


\section{METHODS}

\section{Patients}

Forty-four leprosy patients regardless clinical form and specific leprosy treatment with multidrug therapy (MDT), as proposed by the World Health Organization (WHO), participated in the study. The diagnosis of leprosy was made based on the Ridley and Jopling classification criteria ${ }^{16}$. Patients were selected consecutively based on presence of oral infections at the Leprosy Clinics of the School of Medicine of Ribeirão Preto, University of São Paulo, and were divided into two groups matched by age, sex, and ethnic: group I consisted of leprosy patients presenting some oral infections, and group II consisted of leprosy patients without oral infections. The oral infections considered were: periodontal diseases (PD), irreversible pulpitis (IP), pulpal necrosis (PN) and inflammatory periapical lesions (IPL). Inclusion criteria were: at least one tooth with a probing pocket depth $>4 \mathrm{~mm}$ at two sites, or at least one tooth with some symptomatic or asymptomatic dental diseases (IP, PN or IPL). The control group consisted of patients without leprosy presenting oral infections in order to evaluate if the oral infection alone could stimulate cytokines production at the same way than in leprosy patients. Subjects were excluded if they presented a co-existing local or systemic infection [human immunodeficiency virus (HIV), hepatitis $\mathrm{C}$ virus (HCV) and hepatitis B virus (HBV)] or diabetes mellitus, and if they had received antimicrobial treatment for oral infections in the previous 6 months.

\section{Study design}

After the diagnosis of leprosy and of oral disease, patients from the three Groups (I, II and control) were instructed about oral hygiene techniques and supragingival prophylaxis. Leprosy patients were reexamined 7 days after completion of the dental and/or periodontal treatment (Group I) or dental prophylaxis (Group II). Blood samples were collected into heparinized vacutainers immediately before and 7 days after controlling the oral infection in the Group I, before and 7 days after dental prophylaxis in the Group II, and during oral infection process in control group.

\section{Intracellular cytokine evaluation}

Fluorescein isothiocynate-conjugated (FITC) monoclonal antibodies for cell surface antigens (anti-CD3) or phycoerythrinconjugated (PE) monoclonal antibodies to human cytokines (anti-IFN- $\gamma$, anti-IL-2, anti-IL4 and anti-IL-10) were obtained from Becton Immunocytometry System (BD, San Jose, CA, EUA).

Cell stimulation: to evaluate the percentage of cluster of differentiation 3 (CD3)+ cells presenting IL-2, IL-4, IL-10 and IFN- $\gamma$ staining, PBMCs were separated by gradient density, resuspended in tissue culture (RPMI, Sigma), and stimulated with $25 \mu \mathrm{g} / \mathrm{mL}$ of $4 \alpha$-phorbol 12-myristate 13-acetate (PMA, Sigma) and $1 \mu \mathrm{g} / \mathrm{mL}$ of ionomycin (IONO, Sigma) in the presence of brefeldin (BF) for $4 \mathrm{~h}$ (IFN- $\gamma$ ) or $24 \mathrm{~h}$ (IL-2, IL-4 and IL-10) at $37^{\circ} \mathrm{C}$ with $7 \% \mathrm{CO}_{2}$.
Staining for intracellular antigens: all incubations were performed in the dark. Cells were stained for cell surface antigens using $1 \mu \mathrm{L}$ of anti-CD3 FITC for $20 \mathrm{~min}$ at $4^{\circ} \mathrm{C}$. Staining was stopped and cells were fixed with $1 \mathrm{~mL}$ fluorescence-activated cell sorting (FACS) lysing solution (BD) and permeabilized with $500 \mu \mathrm{L}$ of a FACS permeabilizing solution (BD) at room temperature. Next, $3 \mu \mathrm{L}$ of each anti-cytokine was added to each tube and the preparation was incubated at room temperature for 30 minutes. Finally, cells were resuspended in $500 \mu \mathrm{L}$ of phosphate-buffered saline (PBS) with 1\% paraphormaldehyde (Sigma).

Flow cytometry analyses (FACS). Intracellular production was evaluated by FACS. Samples were run on a FACSort and CellQuest software (BD). A total of 10,000 events were obtained for $\mathrm{CD}^{+}$samples.

\section{Statistical analysis}

The differences in age between the three groups were analyzed by the Kruskal-Wallis test. The association between gender and the three groups, and between clinical classification, reactional episodes and the leprosy groups were analyzed by the chi-Square test. The association between race and the three groups was analyzed by Fisher's exact test. The differences in intracellular cytokines between the three groups (Group I, II, and controls) were compared by the Kruskal-Wallis test with a Dunn post-test, and the differences between baseline values were compared to those obtained after 7 days (only for groups I and II) by the Wilcoxon test. These analyses were performed using the GraphPad Prism software (San Diego, CA, USA). Data were reported as absolute and percentage frequencies, medians and range or means and standard deviations (SD), and the level of significance was set at $5 \%$ in all analyses.

\section{Ethical considerations}

The study was approved by the Ethics Committee of Medical School of Ribeirão Preto, São Paulo University, Brazil (\#15688/2005). All subjects gave written informed consent to participate.

\section{RESULTS}

\section{Patients}

Six of the initial 44 leprosy subjects were excluded from the study, four of them because they did not conclude the dental treatment, and two because of a worsening of their general condition. The final enrolled sample consisted of 38 leprosy patients (28 men and 10 women, mean \pm SD age $43.92 \pm$ 2.12 years; range 18-81 years) before, during or after specific leprosy treatment (multidrug therapy-WHO), and 10 healthy patients, as a control Group (Table 1). Group I consisted of 19 leprosy patients (13 men and 6 women, mean age $45.05 \pm$ 6.3 years; range $18-72$ years) presenting some oral infections: seven patients presented dental diseases (IP, PN and IPL), 3 presented $\mathrm{PD}$, and 9 presented a combination of dental diseases (PN and IPL) and PD. In this group, 8 patients presented lepromatous leprosy (LL), 4 were borderline lepromatous (BL), 2 borderline borderline (BB), 3 borderline tuberculoid (BT), and 
TABLE 1 - Demographic and clinical data of the leprosy patients presenting oral infections (Group I), leprosy patients without oral infections (Group II) and non-leprosy patients presenting oral infections (Control group).

\begin{tabular}{|c|c|c|c|c|}
\hline Variables & $\begin{array}{l}\text { Group I } \\
(n=19)\end{array}$ & $\begin{array}{c}\text { Group II } \\
(n=19)\end{array}$ & $\begin{array}{l}\text { Control group } \\
\qquad(\mathrm{n}=10)\end{array}$ & p-value \\
\hline \multicolumn{5}{|l|}{$\overline{\text { Age }}$} \\
\hline \multicolumn{5}{|l|}{ Gender } \\
\hline male & $13(68.4)$ & $15(78.9 \%)$ & $6(60 \%)$ & $0.54 * *$ \\
\hline \multicolumn{5}{|l|}{ Race } \\
\hline white & $13(68.4 \%)$ & $16(84.2 \%)$ & $6(60 \%)$ & $0.46 \dagger$ \\
\hline african-American & $5(26.3 \%)$ & $3(15.8 \%)$ & $3(30 \%)$ & \\
\hline asian & $1(5.3 \%)$ & $0(0.0 \%)$ & $1(10 \%)$ & \\
\hline BT & $3(15.8 \%)$ & $7(36.8 \%)$ & - & \\
\hline $\mathrm{BB}$ & $2(10.5 \%)$ & $2(10.5 \%)$ & - & \\
\hline $\mathrm{BL}$ & $4(21.1 \%)$ & $2(10.5 \%)$ & - & \\
\hline LL & $8(42.1 \%)$ & $5(26.3 \%)$ & - & \\
\hline \multicolumn{5}{|l|}{ Reactional episodes } \\
\hline ENL & $15(78.9 \%)$ & $2(10.5 \%)$ & - & $<0.01 * *$ \\
\hline $\mathrm{RR}$ & $3(15.8 \%)$ & $4(21.1 \%)$ & - & \\
\hline none & $1(5.3 \%)$ & $13(68.4 \%)$ & - & \\
\hline
\end{tabular}

TT: tuberculoid leprosy; BT: borderline tuberculoid leprosy; BB: borderline; BL: borderline lepromatous leprosy; LL: lepromatous leprosy; RR: reversal reaction; ENL: erythema nodosum leprosum; SD: standard variation. *Kruskal-Wallis test with a Dunn post-test; **Chi-square test; $\uparrow$ Fisher's exact test.

2 tuberculoid (TT). Group II consisted of 19 patients (15 men and 4 women, mean age $42.8 \pm 13.4$ years; range 21-81 years) without oral infections. In this group, 5 patients presented LL, $2 \mathrm{BL}, 2 \mathrm{BB}, 8 \mathrm{BT}$ and $2 \mathrm{TT}$ form. The control Group consisted of 10 male patients (mean \pm SD age $45.7 \pm 8.48$ years; range 42-58) presenting oral infections: three patients with dental diseases (IP and PN), 3 with PD, and 4 with a combination of dental diseases (IP) and PD.

\section{Reactional episodes}

At the time of recruitment, high number of patients from Group I presented RE, compared with Group II ( $<<0.01$, chiSquare test; Table 1): 15/19 (78.9\%) patients in group I presented ENL ( 8 LL, 4 BL, 2 BB, and $1 \mathrm{BT}$ ), three (15.8\%) patients had reversal reaction (2 BT and $1 \mathrm{BL}$ patients) and only one (5.3\%) patient did not present reactional episodes. Two $(10.5 \%)$ of nineteen patients in Group II presented ENL (1 LL and 1 BL patients), four (21\%) patients had reversal reaction (2 TT, 1 BT and $1 \mathrm{BB}$ patients) and thirteen (68.4\%) patients did not present reactional episodes. After dental and/or periodontal treatment, $68.4 \%$ (13/19) of Group I patients presented improvement of the clinical manifestations of reactional episodes, mainly erythema nodosum leprosum (ENL). No clinical alteration was verified in Group II between the two analyses.

\section{Intracellular cytokines}

Low percentages of CD $3+$ lymphocytes bearing IL-2, IL-10 and IFN- $\gamma$ were observed in the Group I (leprosy patients with oral infections) and Group II (leprosy patients without oral infections) at baseline and 7 days after therapy or prophylaxis compared to controls (non-leprosy patients with oral infection) (Table 2 and Figures 1A, 1C and 1D). Likewise, group I showed reduced percentages of IL- 4 at baseline and 7 days after therapy compared to controls ( $\mathrm{p}<0.05$, Kruskal-Wallis test with a Dunn post-test), and the Group II showed reduced percentages of $\mathrm{CD}^{+}$cells bearing IL-4 compared to control group (Table 2 and Figure 1B), although there was no statistical difference. An increase of the percentages of $\mathrm{CD}^{+}$cells bearing IL-4 and IFN- $\gamma$ was observed in the Group I after the oral infections treatment ( $p<0.05$, Wilcoxon test) (Table 2 and Figures 1B and 1D). There was no evidence of differences in the remaining comparison between groups. 
TABLE 2 - Percentage of $C D 3^{+}$T cells producing IL-2, IL-4, IL-10, and IFN- $\gamma$ after in vitro activation with PMA and ionomycin from PBMCs of leprosy patients with oral infections (Group I), leprosy patients without oral infections (Group II) and non-leprosy patients with oral infections (control Group). Results are expressed as median (range).

\begin{tabular}{|c|c|c|c|c|c|}
\hline & \multicolumn{2}{|c|}{$\begin{array}{l}\text { Group I } \\
(n=19)\end{array}$} & \multicolumn{2}{|c|}{$\begin{array}{l}\text { Group II } \\
(n=19)\end{array}$} & \multirow{2}{*}{$\begin{array}{l}\text { Control Group } \\
\qquad(\mathrm{n}=10)\end{array}$} \\
\hline & baseline & 7 days after therapy & baseline & 7 days after prophylaxis & \\
\hline $\mathrm{CD3}^{+} / \mathrm{IL}-2$ & $17.19(0.00-43.8)$ & $23.57(0.00-52.48)$ & $21.24(0.02-51.5)$ & $20.20(0.00-50.8)$ & $43.08(28.86-84.42)$ \\
\hline $\mathrm{CD3}^{+} / \mathrm{IL}-4$ & $0.14(0.00-1.61)$ & $0.61(0.00-5.91)$ & $0.64(0.00-2.74)$ & $1.12(0.00-4.12)$ & $1.89(0.00-4.17)$ \\
\hline
\end{tabular}

CD3 $^{+ \text {: }}$ cluster of differentiation $3^{+}$; IL-2: interleukin-2; IL-4: interleukin-4; IL-10: interleukin-10; IFN- $\gamma$ : interferon- $\gamma$; PMA: 40-phorbol 12-myristate 13-acetate; PBMCs: peripheral blood mononuclear cells.

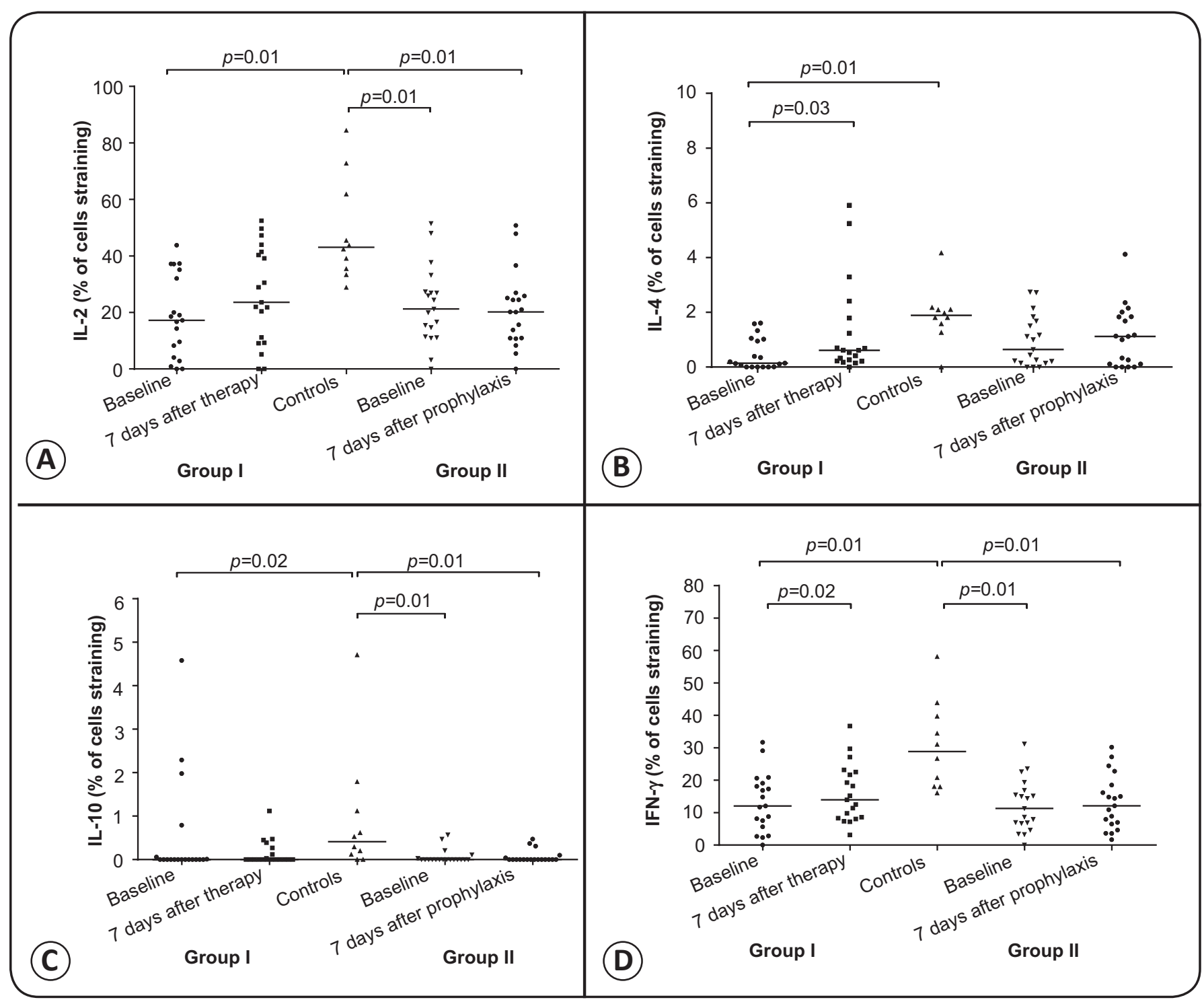

FIGURE 1 - Comparisons between the percentages of CD3+T cells producing IL-2 (A), IL-4 (B), IL-10 (C) and IFN- $\gamma$ (D) from PBMCs of leprosy patients with oral infection (group I; $n=19$ ), at baseline and 7 after oral infections therapy; leprosy patients without oral infection (group II; $n=19)$, at baseline and 7 days after dental prophylaxis; and non-leprosy patients with oral infection (control; $n=10$ ), during the infectious process. The horizontal lines represent the median of each group. PBMCs were stimulated with PMA and ionomycin for $4 \mathrm{~h}(I F N-\gamma)$ or $24 \mathrm{~h}(I L-2$, IL-4 and IL-10). The horizontal lines represent the median of each group.

IL-2: interleukin-2; IL-4: interleukin-4; IL-10: interleukin-10; IFN- $\gamma$ : interferon- $\gamma$; PBMCs: peripheral blood mononuclear cells. PMA: 4 $\alpha$-phorbol 12-myristate 13-acetate. 


\section{DISCUSSION}

Usually the peripheral profile of cytokines in leprosy (serum and plasma) reflects the measure of many sources of cytokine production ${ }^{17,18}$ without identifying which specific cell is really compromised $^{19,20}$. It has been observed that PBMCs present different levels of proliferation index of cytokines when they are stimulated in vitro with Mycobacterium leprae extracts ${ }^{21-23}$. On the other hand, we observed that the leprosy reactional episodes are frequent in patients presenting oral infections ${ }^{14,15}$ and other coinfections ${ }^{24}$. Therefore, this study attempted to clarify whether chronic oral infections could influence the intracellular production of cytokines in leprosy patients, and to verify the relationship with the development of reactional episodes.

Cytokines like IFN- $\gamma$ are believed to be essential for the activation of macrophages and for inducing the destruction of intracellular Mycobacterium leprae, leading to specific activation and differentiation of $\mathrm{T}$ cells, modulated by IL-2, IL-12 and IL-18, resulting in infection control and granuloma formation $^{21,26,27}$. At the other end of the leprosy spectrum, the immunity is mediated by IL-4 and IL-10, regulatory cytokines able to block macrophage activation and exacerbation of humoral immunity, resulting in an increased bacterial load ${ }^{28}$.

The evaluation of intracellular cytokines that have a pathogenic role in leprosy showed a low quantity of $\mathrm{CD}^{+}$cells that stained for IL-2 in leprosy patients, more accentuated in patients with oral coinfection compared to control, suggesting that the infectious process by $M$. leprae can reduce the IL-2 response. Similar results were found in $\mathrm{CD}^{+}$cells that stained for IFN- $\gamma$ with significantly diminished detection in leprosy patients compared to controls, and the most interesting find was that oral infections treatment can induce an increase of IFN- $\gamma$ (Figure 1D). Then, it we may suggest that the differentiation of $\mathrm{CD}^{+}$cells to the Th1 type is depressed in leprosy and the oral coinfection could act by augmenting the pro-inflammatory response mediated by IFN- $\gamma$.

$\mathrm{CD}^{+}$cells stained for IL-4 showed low percentages in leprosy patients with oral infections compared to leprosy patients without oral infection and controls, and the oral infection treatment induced an increased production of this cytokine $(\mathrm{P}=0.03$; Figure 1B), suggesting that oral infection can depress the immunoregulatory activity of IL4 while maintaining the pro-inflammatory activity of IFN- $\gamma$, resulting in exacerbation of the inflammatory reaction. Additionally, the percentage of $\mathrm{CD}^{+}$cells stained for IL-10 was similar in leprosy patients with oral infection (Group I) and leprosy patients without oral infection (Group II), and the oral infection control did not influence these results. Both leprosy groups (I and II) showed reduced production of this cytokine compared to control group. Since IL-10 has been considered to be an anti-inflammatory cytokine that can regulate the Th1 pattern of the cellular immune response $\mathrm{e}^{29,30}$, it is possible to consider that the coinfection acts on the course of leprosy infection in two ways: worsening the specific immunological response of the leprosy patients and favoring the inflammatory reaction, clinically manifested as a reactional episode.
The coexistence of oral chronic infections with leprosy can modulate the inflammatory reaction by elevation of the intracellular inflammatory markers expression, probably stimulating a spill-over of these inflammatory products into the peripheral circulation where they can act as inducers of an inflammatory reaction, exacerbating the insidious chronic evolution of leprosy and, consequently, acting like an inducer, stimulatory or maintaining factor in leprosy reactions ${ }^{14,15,24}$. In addition, the presence of these chronic infections can influence the production of intracellular cytokines, and can reflect the fact that most of the leprosy patients with coinfection (Group I) presented reactional episodes, corroborating the hypothesis of a synergistic action of the two kinds of inflammatory reaction on the course of leprosy. A limitation of the study was not match properly the leprosy groups by clinical form, and the small number of patients. Possibly, studies with larger numbers of patients properly matched by clinical leprosy forms might assess the impact of oral coinfections on occurrence of leprosy reactional episodes.

\section{ACKNOWLEDGMENTS}

We thank Mrs Camila Cristina de Oliveira Menezes Bonaldo for assistance with sample analysis.

\section{CONFLICT OF INTEREST}

The authors declare that there is no conflict of interest.

\section{FINANCIAL SUPPORT}

The study was funded by National Council for Scientific and Technological Development - CNPq (grants 154806/2006-4 and 481399/2008-9), the São Paulo State Foundation against Leprosy (grant 110), and the Foundation of Support to Teaching, Research and Assistance of HCFMRP-USP (FAEPA).

\section{REFERENCES}

1. Jopling WH. Classification of reaction in leprosy. Leprosy Rev 1970; 41:62-63.

2. Seghal VN, Sharma V. Reactions in leprosy - a prospective study of clinical, bacteriological, immunological and histopathological parameters in thirty-five Indians. J Dermatol 1988; 15:412-419.

3. Rea TH, Modlin RL. Immunopathology of leprosy skin lesions. Semin Dermatol 1991; 10:188-193.

4. Cuevas J, Rodríguez-Peralto JL, Carrillo R, Contreras F. Erythema nodosum leprosum: reactional leprosy. Sem Cutan Med Surg 2007; 26:126-130.

5. Manandhar R, Shrestha N, Butlin CR, Roche PW. High levels of inflammatory cytokines are associated with poor clinical response to steroid treatment and recurrent episodes of type 1 reactions in leprosy. Clin Exp Immunol 2002; 128: 333-338.

6. Sarno EM, Grau GE, Vieira LM, Nery JA. Serum levels of tumor necrosis factor - alpha and interleukin 1 beta during leprosy reactional states. Clin Exp Immunol 1991; 84:103-108.

7. Goulart IMB, Penna GO, Cunha G. Imunopatologia da hanseníase: a complexidade dos mecanismos da resposta imune do hospedeiro ao Mycobacterium leprae. Rev Soc Bras Med Trop 2002; 35:365-375.

8. Lima MCBS, Pereira GMB, Rumjanek FD. Immunological cytokine correlates of protective immunity and pathogenesis in leprosy. Scand J Immunol 2000; 51:419-428. 
9. Krutzik SR, Ochoa MT, Sieling PA, Uematsu S, Ng YW, Leqaspi A, et al. Activation and regulation of toll-like receptors 2 and 1 in human leprosy. Nat Med 2003; 9:525-532.

10. Bonfitto NLB, Motta ACF, Furini RB, Komesu MC, Nascimento MMP, Figueiredo JFC, et al. Determination of the salivary anti-phenolic glycolipid-1 antibody in leprosy patients as a tool to monitoring multidrugtherapy. Am J Infect Dis 2009; 5:321-326.

11. Motta AC, Pereira KJ, Tarquínio DC, Vieira MB, Miyake K, Foss NT. Leprosy reactions: coinfections as a possible risk factor. Clinics 2012; 67:1145-1148.

12. Jeffcoat MK, Geurs NC, Reddy MS, Cliver SP, Goldenberg RL, Hauth JC. Periodontal infection and preterm birth: results of a prospective study. J Am Dent Assoc 2001; 132:875-880

13. Marcaccini AM, Meschiari CA, Sorgi CA, Saraiva MC, Souza AM, Faccioli LH, et al. Circulating interleukin-6 and high-sensitivity C-reactive protein decrease after periodontal therapy in otherwise healthy subjects. J Periodontol 2009; 80:594-602.

14. Motta ACF, Furini RB, Simão JCL, Ferreira MAN, Komesu MC, Foss NT. The recurrence of leprosy reactional episodes could be associated with oral chronic infections and expression of serum IL-1, TNF-á, IL-6, IFN-ã and IL-10. Braz Dent J 2010; 21:158-164.

15. Motta ACF, Furini RB, Simão JCL, Vieira MB, Ferreira MAN, Komesu MC, et al. Could leprosy reactional episodes be exacerbated by oral infections? Rev Soc Bras Med Trop 2011; 44:633-635.

16. Ridley DS, Jopling WH. Classification of leprosy according to immunity: a five-group system. Int J Lepr Other Mycobact Dis 1966; 34:255-273.

17. Araujo Stefani MM, Guerra JG, Souza ALM, Costa MB, Oliveira ML, Martelli $\mathrm{CT}$, et al. Potential plasma markers of type 1 and type 2 leprosy reactions: a preliminary report. BMC Infectious Diseases 2009; 9:1-8.

18. Iyer A, Hatta M, Usman R, Luiten S, Oskam L, Faber W, et al. Serum levels of interferon, tumor necrosis factor-á, soluble interleukin-6R and soluble cell activation markers for monitoring response to treatment of leprosy reactions. Immunopathol Lepr 2007; 150:210-216.

19. Antas PRZ, Sales JS, Pereira KC, Oliveira EB, Cunha KS, Sarno EN, et al. Patterns of intracellular cytokines in CD4 and CD8 T cells from patients with mycobacterial infections. Braz J Med Biol Res 2004; 37:1119-1129.
20. Foss-Freitas MC, Foss NT, Donadi EA, Foss MC. Effect of the glycemic control on intracellular cytokine production from peripheral blood mononuclear cells of type 1 and type 2 diabetic patients. Diab Res Clin Prac 2008; 82:329-334.

21. Lopez Roa RI, Guerrero Velásquez C, Alvarado Navarro A, Montoya Buelna M, Garcia Niebla C, Fafutis-Morris M. Recovery of IFN-gamma levels in PBMCs from lepromatous leprosy patients through the synergistic actions of the cytokines IL-12 and IL-18. Int Immunopharmacol 2008; 20:1715-1720.

22. Islas-Rodriguez AE, Morales-Ortiz R, Fafutis-Morris M, Gonzalez-Mendoza A, Ortiz-Ortiz L. Deficiency in the biosynthesis of interleukin 2 (IL-2) and functional presence of the IL-2 receptor in lepromatous leprosy. Int J Lepr Other Mycobact Dis 1987; 55:566-569.

23. Fafutis-Morris M, Guillen-Vargas CM, Navarro-Fierros S, Alfaro-Bustamante F, Zaitseva-Petrovna G, Daneri-Navarro A, et al. Addition of anti-CD28 antibodies restores PBMC proliferation and IFN-ã production in lepromatous leprosy patients. J Interferon Cytokine Res 1999;19:1237-1243.

24. Rego VPA, Machado PRL, Martins I, Trindade R, Paraná R. Type 1 reaction in leprosy: characteristics and association with hepatitis $\mathrm{B}$ and $\mathrm{C}$ viruses. Rev Soc Bras Med Trop 2007; 40:546-549.

25. Sieling PA, Modlin RL. Cytokine patterns at the site of mycobacterium infection. Immunobiology 1994; 191:378-387.

26. Nakahira M, Ahn HJ, Park WR, Gao P, Tomura M, Park CS, et al. Synergy of IL-12 and IL-18 for IFN-gamma gene expression: IL-12-induced STAT4 contributes to IFN-gamma promoter activation by upregulating the binding activity of IL-18 induced activator protein. J Immunol 2002; 168:1146-1153.

27. Guerrero-Velázquez C, Lopez-Roa RI, Delgado-Rizo V, Guillen-Vargas CM, Montoya-Buelna M, Fafutis-Morris M. Abnormalities in intracellular processing and expression of interferon-ã receptor in adherent cells from lepromatous leprosy patients. J Interferon Cytokine Res 2010;30: 99-105.

28. Volk H, Asadullah K, Gallagher G, Sabat R, Grutz G. IL-10 and its homologs: important immune mediators and emerging immunotherapeutic targets. Trend Immunol 2001; 22:414-417.

29. Mocellin S, Marincola F, Rossi CR, Nitti D, Lise M. The multifaceted relationship between IL-10 and adaptative immunity: putting together the pieces of a puzzle. Cytokine Growth Factor Rev 2004; 15:61-76. 